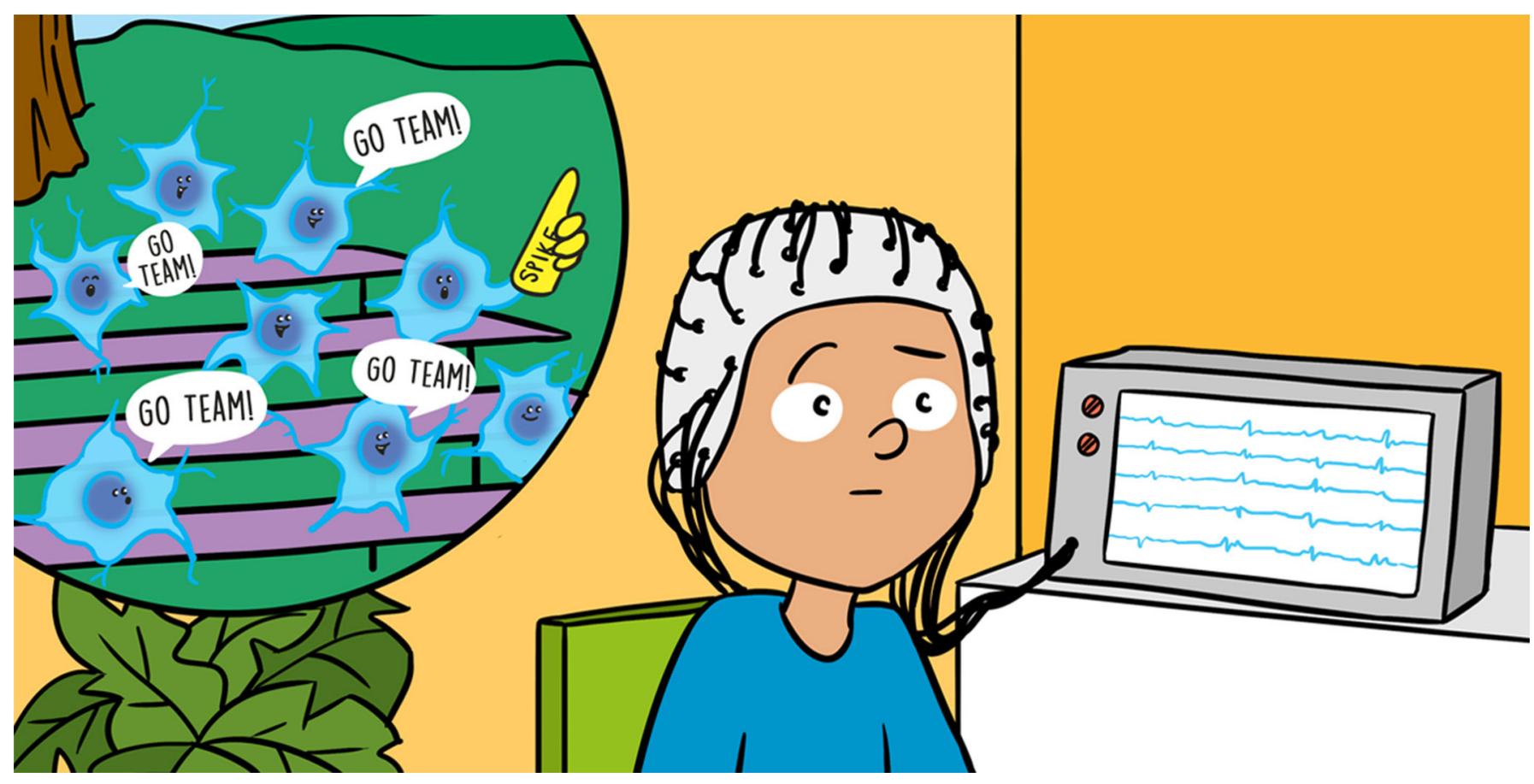

\title{
WHAT IS EPILEPSY AND HOW CAN YOU HELP SOMEONE WITH IT?
}

\section{Stephanie L. Rogers and György Buzsáki*}

School of Medicine, The Neuroscience Institute, New York University, New York, NY, United States

\section{YOUNG REVIEWERS:}

191. $\begin{aligned} & \text { FRIENDS } \\ & \text { SEMINARY } \\ & \text { AGES: 12-14 }\end{aligned}$

\section{EPILEPSY}

A neurological disorder that causes a person to have seizures.
Would you know what to do if someone had a seizure? Do you know what a seizure looks like? More than 50 million people around the globe have epilepsy. Epilepsy is a brain disorder in which the patient has seizures. Epilepsy is one of the most common brain disorders, but also one of the most misunderstood. Patients with epilepsy are often met with fear and confusion, because others do not fully understand what a seizure is or how to help someone who is having a seizure. Myths linked the disorder with the spirits and gods. These myths influenced the types of first-aid practices and treatments for seizures and. In this article, you will learn the history of epilepsy, what happens in the brain during a seizure, what seizures look like, and how to give proper first aid to someone having a seizure.

\section{INTRODUCTION}

Epilepsy is one of the most common brain disorders, and it causes seizures. It occurs in about one in every 26 people. That means that if 
SEIZURE

Abnormal electrical activity in the brain that changes the behavior of a person.
60 people are in your class, it is likely that 2 of them will have epilepsy. Epilepsy has been around since the beginning of time and has been called many names, including the "sacred disease" and the "falling sickness" [1]. There are many famous people with epilepsy, including Julius Caesar, Prince, and Lil' Wayne. Even though epilepsy is so common, it is one of the most misunderstood disorders. This could be because, in many parts of the world, epilepsy is still associated with the divine. So, patients not only live with the symptoms of epilepsy, but also face the stigma of having a disorder that people do not understand. Stigmas are labels that we give people that make us treat them differently than others. While scientists and doctors have made medications to help with the symptoms, epilepsy medicine only helps $70 \%$ of patients. All patients must still fight the stigmas and how people treat them. This is why epilepsy research is extremely important for human health.

\section{EPILEPSY AND ITS "SACRED" ORIGINS}

What makes epilepsy and seizures so mysterious? Ancient people did not understand what a seizure was. They saw that some people would have unexplained changes in their behavior, and they did not understand why. Some people thought that the gods or spirits were involved in seizures. The Romans called epilepsy the sacred disease, thinking that gods talked to people during seizures. In the Middle Ages, people believed that seizures were caused by a demon inside the body who invisibly "seized" the person. Hence the name seizure. Fear spread quickly and soon people believed that even breathing the same air as an epileptic patient could let the demon travel to other people [2]. Therefore, people with seizures were isolated and restrained. Their "doctors" were priests who tried to send the demon away. Not only were these treatments unhelpful, but they could also be dangerous for the patients. To provide the right treatment, doctors needed to know the cause of epilepsy. In the Middle Ages, they did not know what we know now. Today we know that seizures happen in the brain. The brain is responsible for almost every aspect of our behavior. The brain detects scents, creates our feelings, and holds our memories. Because seizures happen in the brain, they can change our awareness. Seizures can make epilepsy patients hear sounds that are not there or make parts of their bodies move without patients' knowledge.

\section{THE DAWN OF MEDICAL SCIENCE AND A BETTER UNDERSTANDING OF SEIZURES}

New medical devices and more careful and accurate observation of seizures helped us learn more about epilepsy. The brain produces electricity that doctors and scientists can detect with recently invented 


\section{NEURON}

A brain cell.

\section{ELECTROENCEPHA-} LOGRAPHY (EEG)

A medical practice where electrodes are put on the scalp to read the electrical signals of the brain.

\section{Figure 1}

Measuring brain activity with electrodes.

(A) An example of an EEG recording system on a human subject. The arrows point to electrodes, which will have a special gel on them to help them read the electrical activity from the brain. This information is given to a computer for visualization and analysis. (B) An example, in cartoon form, of typical electrode placement on the scalp of a patient and the readout from the electrodes. Each electrode is one "channel," which is its own row in the readout. The lines for each channel correspond to changes in electricity in the brain over the time of the measurement. Examples of abnormal activity in the brain of a patient are circled in red. Images generously provided by András Horváth MD, Ph.D. tools. Some of these tools show what happens in the brain during a seizure. Brain cells are also called neurons. Neurons in the brain communicate using electrical signals, like computers do. We can put sensors, called electrodes, on the scalp of a patient (Figure 1A) and see the pattern of electricity in the brain (Figure 1B). This is how an electroencephalography (EEG) works. Doctors use EEG to observe changes in brain activity that could be caused by seizures.

Thanks to EEG and other advancements, we have a better understanding of what happens during seizures. Seizures happen when many neurons activate, or "fire" together, and this firing may change a person's behavior. But what does this mean in terms of what the neurons are doing? Imagine that you are at a football game with your friends. At any given moment, you and your friends are talking. The group behind you is having their own conversation. Two people to your left are silently watching the game, etc. Basically, each group is only paying attention to the conversation or activity they are directly involved in. Then, one rowdy student in the stands begins a chant. Slowly, everyone in your section stops their individual conversations and joins in the chant. And now, what once was a section of independent groups doing separate activities is now all doing the same thing. The region is unified, doing and saying the exact same thing at the exact same time. What you were doing before the chant does not predict the chant happening. This is what we call synchrony, and it is what happens to brain cells during an epileptic seizure. Regardless of what the neurons were doing before, now they chant together. We can see this chant on an EEG as "spikes." Doctors look for these spikes, followed by a rest period, to confirm that a seizure happened.

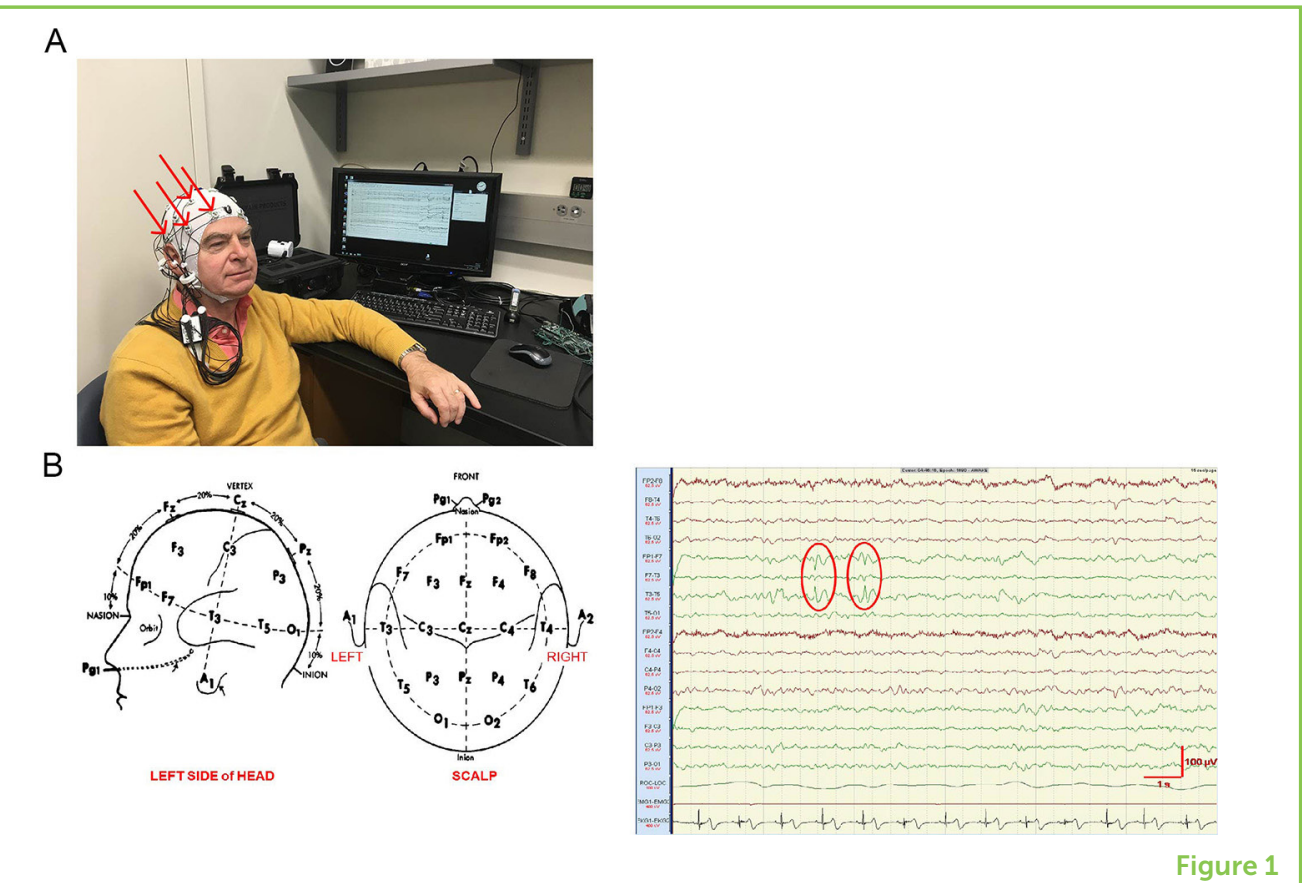




\section{DIFFERENT TYPES OF SEIZURES}

Anyone can have a seizure. Most often seizures do not look like the person is shaking. In fact, there is one type of seizure in which the person just stares. You may think that the person is just "spacing out" or daydreaming, but he may actually be experiencing a seizure! How can seizures look so different from each other? Well, the brain has different regions that control different things. What a seizure looks like depends on how big the chant is and in which brain region the chant happens. For example, if the chant is small and only happens in the brain area for vision, the seizure may only appear as flashes of light. Doctors call this type of seizure focal, because it happens in only a small area of the brain. Any part of the brain can have a focal seizure, like the frontal lobe responsible for emotions or the auditory cortex responsible for hearing. Sometimes, cells from many different brain regions can join in the chant. When this happens, the seizure is called "generalized." One type of generalized seizure is when a person falls to the ground and his or her limbs begin to shake. This is the type of seizure that is most often shown in movies and TV shows. However, this is only one type of seizure.

There are many different ways to get epilepsy. Some people get epilepsy from injuries to the head, like falling and bumping the head. Some people get epilepsy from a virus or bacteria that goes to the brain. Some people simply inherit it from their ancestors. For many people, we do not actually know how they got epilepsy.

You can be diagnosed with epilepsy at any point in your life. Many patients have their first seizure in childhood. But there are also patients who get epilepsy when they are adults. It all depends on what happens to cause the epilepsy. Epilepsy due to genes usually happens in childhood. Epilepsy from infections or injury can happen any time.

\section{WHAT TO DO WHEN SOMEONE HAS A SEIZURE}

Even though there are many types of seizures, first-aid for all seizures is similar. Now let us test your knowledge with a little quiz!

What would you do if someone had a seizure? Choose ONE answer

(a) Put a tongue depressor in his/her mouth to prevent swallowing the tongue

(b) Restrain the person so his/her arms cannot move 
(c) Remove any hazards from the area and keep the person as safe as possible, interfering as little as possible

If you answered "c," then congratulations, you are a seizure first-aid pro! If the seizure involves movement (a motor seizure), it may feel like the right thing to do is to hold the person down. You may feel like you want to hold down the parts of the body that are moving. But this is wrong. You should never hold down a person who is having a seizure. Remember, the person is not aware of his or her body movements and is not in control of them. As long as the neuronal chant is happening in the brain, the body will move. If you try to hold a person down, the body will still move, and you could cause a pulled muscle or dislocated joint! If the seizure involves movement, remove any hazards that could make the person trip and fall. If the person is near the corner of a table or a staircase, stand in front of the person and gently guide him or her away from the danger (Figure 2A). If the person falls and is shaking all over (also called a convulsion), then lay the person on his or her side. Place something soft under the head to prevent head injury. This can be a bunched-up shirt or a jacket, if you cannot find a pillow. If the person wears glasses, remove them (Figure 2B). Remember, not all seizures look alike, because they depend on the origin, type, and severity of the epilepsy. Because of this, some patients have triggers, like strobe lights, that cause them to have seizures. But not everyone with epilepsy will have a seizure if there are strobe lights. In fact, many people do not have known triggers for their seizures. Again, this depends on the type of epilepsy and where in the brain the seizures come from. Usually, seizures will last for about $30 \mathrm{~s}$. But no matter what type of seizure it

Figure 2

How to provide proper first aid to a person having a seizure.

(A) These cartoons show common types of focal seizures and the proper first aid for these types of seizures

(B) This cartoon shows the proper first aid for a person who is having a convulsion. Remember always time seizures and call and 911 if the seizure lasts longer than three minutes. Stay with the person until he or she is fully aware and is not feeling confused. Cartoons generously provided by the Epilepsy Foundation of Eastern Pennsylvania.

is, if it lasts more than 3 min you should call 911.

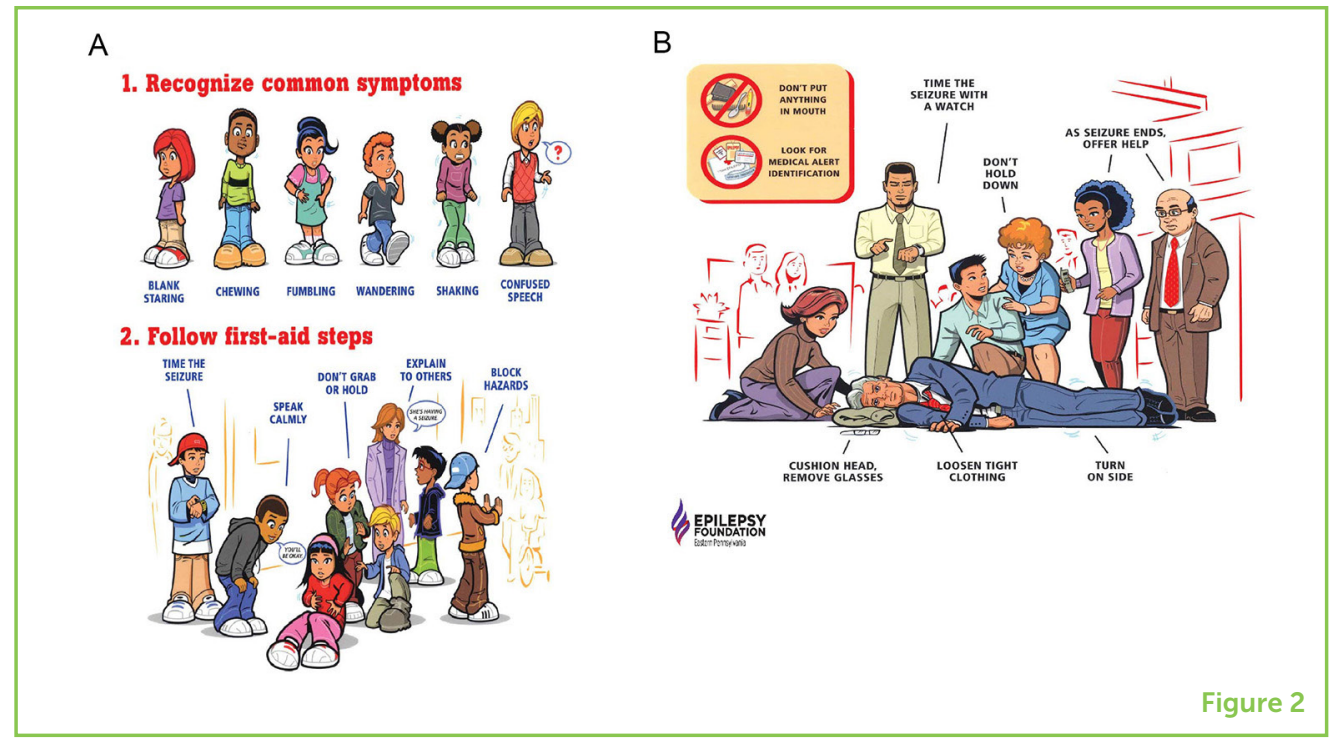




\section{THE FUTURE OF EPILEPSY CARE}

Even though doctors and scientists have made many discoveries to help with defining and treating epilepsy, we are not done yet! We have medication that stops seizures from happening for $70 \%$ of patients. However, the medicines we have do not help $30 \%$ of patients with epilepsy. Scientists are trying to understand why these drugs do not work well in those patients, and also trying to create new drugs. Scientists also study seizures to try to find new ways to prevent the chant from happening in the brain. This is a difficult task, because there are so many different ways a chant can start in the brain. This is why epilepsy research is so important. We need to create better drugs to help the $30 \%$ of people whose seizures are not controlled. Think about becoming a neuroscientist if you would like to join the fight against epilepsy.

\section{REFERENCES}

1. DeBacco, T. V. 1995. The Mystery of Epilepsy. The Washington Post. Available online at: www.washingtonpost.com/archive/lifestyle/wellness/1995/11/28/ the-mystery-of-epilepsy/da56eb08-8dcc-4e32-8494-21382f6e52fb/?noredirect=onfutm_term $=.65 e 141322488$ (accessed August 28, 2018).

2. Diamantis, A., Sidiropoulou, K., and Magiorkinis, E. 2010. Epilepsy during the middle ages, the renaissance and the enlightenment. J. Neurol. 257:691-8. doi: 10.1007/s00415-009-5433-7

SUBMITTED: 04 September 2018; ACCEPTED: 14 March 2019; PUBLISHED ONLINE: 29 March 2019.

EDITED BY: Paul William Glimcher, New York University, United States

CITATION: Rogers SL and Buzsáki G (2019) What is Epilepsy and How Can You Help Someone With It? Front. Young Minds 7:52. doi: 10.3389/frym.2019.00052

CONFLICT OF INTEREST STATEMENT: The authors declare that the research was conducted in the absence of any commercial or financial relationships that could be construed as a potential conflict of interest.

COPYRIGHT @ 2019 Rogers and Buzsáki. This is an open-access article distributed under the terms of the Creative Commons Attribution License (CC BY). The use, distribution or reproduction in other forums is permitted, provided the original author(s) and the copyright owner(s) are credited and that the original publication in this journal is cited, in accordance with accepted academic practice. No use, distribution or reproduction is permitted which does not comply with these terms. 

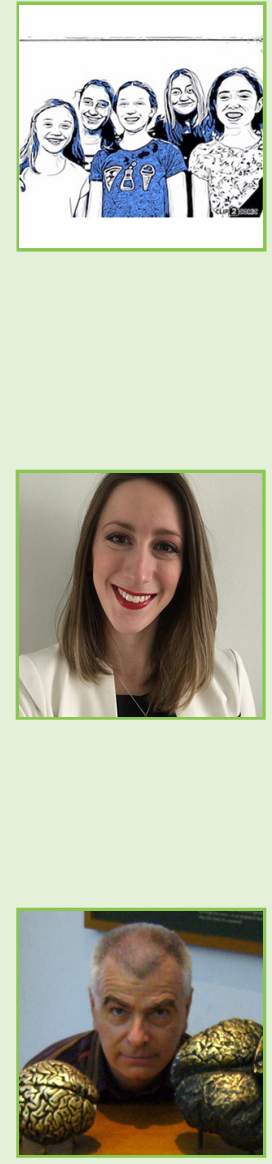

\section{YOUNG REVIEWERS}

\section{FRIENDS SEMINARY, AGES: 12-14}

We are a group of girls who love science, in part for its capacity to effect positive change in the world. We think research about the earth and medicine is exciting, inspiring, and deeply important. We are honored to play a role in spreading awareness about the amazing information the scientific community is discovering!

\section{AUTHORS}

\section{STEPHANIE L. ROGERS}

Stephanie Rogers is currently getting her Ph.D. in neuroscience at NYU. She teaches a human health class for undergraduate students to help demystify biology and our own bodies. She also produces an outreach series called "A Lot on the Mind" that shares patients' stories, experiences, and talents. Stephanie's older sister has untreatable epilepsy and she is the inspiration behind much of Stephanie's outreach work. Stephanie hopes to increase awareness and diminish social stigmas associated with neurological disorders.

\section{GYÖRGY BUZSÁKI}

György Buzsáki is Biggs Professor of Neuroscience at New York University. His main focus is "neural syntax," i.e., how segmentation of neural information is organized by the numerous brain rhythms to support cognitive functions. He is among the top $1 \%$ most-cited neuroscientists, elected member of the National Academy of Sciences USA, Academiae Europaeae and the Hungarian Academy of Sciences. He sits on the editorial boards of several leading neuroscience journals, including Science and Neuron, honoris causa at Université Aix-Marseille, France and University of Kaposvar, Hungary and University of Pécs, Hungary. He is a co-recipient of the 2011 Brain Prize (Books: G. Buzsáki, Rhythms of the Brain, Oxford University Press, 2006; The Brain from Inside Out, OUP, 2019). *gyorgy.buzsakianyumc.org 